Check for updates

Park and St Francis Surgery, Pilgrims Close, Valley Park, Chandlers Ford, Eastleigh S053 4ST, UK

mark.rickenbach@nhs.net Cite this as: BMJ 2021;372:n599 http://dx.doi.org/10.1136/bmj.n599 Published: 02 March 2021

\section{RECRUITMENT INTO COVID-19 TRIALS}

\section{Covid-19 trials: allow recruitment by everyone in healthcare, including those not previously involved in research}

\author{
Mark A Rickenbach GP
}

Darzi and colleagues are right to highlight research recruitment, because, before the pandemic, research activity had fallen in almost all specialties in England. ${ }^{1}$ The Principle study, mentioned, is a step change with full online consent and follow-up. It has allowed recruitment by everyone in healthcare, including those not previously involved in research.

Primary care covers every medical condition and almost every patient in the UK. A trusted GP often knows the patient over many years, and they hold a comprehensive healthcare record. This leads to higher rates of recruitment from direct GP contact. However, it is who undertakes the research, rather than who recruits, which determines funding. Both should be considered by the national Clinical Research Network (CRN) to allow appropriate resource allocation.

More support from research staff firmly embedded in primary care is needed, but the financial risk to individual GPs is significant. The independent contractor model pays GP partners from what is left over when all services have been paid for. Add the risks of taking on staff to a falling income, with widespread closures of GP surgeries, and this can literally lead to loss of a GP's house.

Improved models to fund research staff include additional funds to offset on costs and risk, employment by local CRNs, employment by larger local research hubs, local direct enhanced services arrangements, and primary care network (PCN) based researchers. PCN additional roles have worked well for other staff provided there is full funding, including overheads. Research is already written into national PCN guidance.

We also need more research emerging from primary care. Enhanced support is required to get coalface primary care questions converted into research questions, then into practical National Institute for Health Research accredited research protocols, and finally back into changes in practice.

Competing interests: Primary care adviser and executive member of the Wessex Clinical Research Network.

Full response at: www.bmj.com/content/372/bmj.n235/rr-1.

Darzi A, Goddard A, Henderson K, et al. Increasing recruitment into covid-19 trials. BMJ2021;372:n235. doi: 10.1136/bmj.n235 pmid: 33514589

This article is made freely available for use in accordance with BMJ's website terms and conditions for the duration of the covid-19 pandemic or until otherwise determined by BMJ. You may use, download and print the article for any lawful, non-commercial purpose (including text and data mining) provided that all copyright notices and trade marks are retained. 